\title{
Study on Beech Wood Softening Perceptual Experience Based on the Change of Material Perceptual Elements
}

\author{
$\mathrm{Na}$ Xiong ${ }^{\mathrm{a}}$, Haoming $\mathrm{Li}^{\mathrm{a}}$, Ruoyu $\mathrm{Gu}^{\mathrm{b} 1}$ \\ ${ }^{a}$ Design Innovation Center, China Academy of Art, Hangzhou, China, 310002 \\ ${ }^{\mathrm{b}}$ System Planning Lab of Design Department, Chiba University, Chiba, Japan, 263-
}

8522

\begin{abstract}
This paper aims to establish a material perceptual experience that is different from its physical property through the study of material perception. The study selects beech wood material as the object, and aimed to achieve its softening perceptual experience by changing the visual and tactile perceptual elements. After investigation, the key elements of visual perception (shape and color) and tactile perception (roughness degree and deformation degree) are confirmed as variables to study the relationship with the degree of softening perceptual experience, so as to provide new possibilities for the innovation of material perception experience.
\end{abstract}

Keywords. Material innovation, Perceptual experience, Beech wood

\section{Introduction}

In product design, it is important to focus on both the function of the product and the physical and mental experience of the product to the user [1]. Nowadays, product design innovation is not only the innovation on the conventional level in terms of function, form and usage. In order to enhance the innovation and competitiveness of products, designers have started to rethink the intervention points in product design innovation. As the basis of product design, materials have become an important and indispensable factor in the design process with their own inherent characteristics and emotional semantics [2]. The main role of materials in design is to embody the function and aesthetics [3]. Materials not only have functional properties, but also can resonate with people and have an impact on the perception and experience of a product. In a study of design trends in the 21 st century, most designers and design agencies believe that the key driving force of new products is the offering of new materials [4]. In material innovation, material perception is an important factor affecting the product experience, and human's intrinsic response to the stimulus of perceived materials [5]. Through the information collected by visual, tactile, auditory and olfactory perception elements, combined with users' own experience of materials, perceptual experiences such as cold, hard, warm and soft will be formed. The perceptual experience of a kind of material is usually consistent with its physical properties, so it has formed a mode of fixed thinking

\footnotetext{
${ }^{1}$ Corresponding author: Ruoyu Gu; Postal address: System Planning Lab of Design Department, Chiba University, Chiba, Japan, 263-8522 ; Email address: okonna@163.com
} 
in the minds of designers and users to the perceptual experience of a specific material in the long run, lacking innovation and freshness. Therefore, this paper hopes to create a sense of contrast between perceptual experience and physical properties through the study of material perceptual elements, so as to create a different material perceptual experience and provide a new perspective and possibility for product material innovation.

\section{Perceptual Experience}

Perception is the organization, identification, and interpretation of sensory information in order to represent and understand the presented information or environment [6]. The formation of perception begins with the acquisition of external stimuli information, and then the brain processes various characteristics obtained from external environment such as appearance, sound, smell, temperature, etc., and to generate feeling at the same time. Sensation, in psychology, is defined as the most primary psychological response of an individual caused by external stimuli to the human senses [7]. After deep processing to external environment by the brain, people will obtain the cognition, which is called as sensation.Although perception is based on sensation, it is not a simple combination of multiple senses, it is the process by which we organize sensory information [8]. Feeling and sensation usually cannot be separated completely, feeling is the result of initial processing of information, and sensation is the result of indepth processing of information, both of which constitute the result of perception for external information.

The process of people's perception to external stimulus is from the feeling formed by sense organs, then to sensation formed by processing feeling information, eventually to advanced cognition, which is the subjective experience formed by external stimulus. After this stage, the user' s perception of external environment is truly transformed into experience.Therefore, this paper aims to change the physical properties of materials in terms of visual, tactile, taste and other perceptual elements in the sensory formation stage when people collect material information through their senses organs, thus breaking people's conventional understanding of materials in the cognitive stage and eventually influencing the perceptual experience of materials, to create a material perceptual experience that is different from its physical properties of materials.

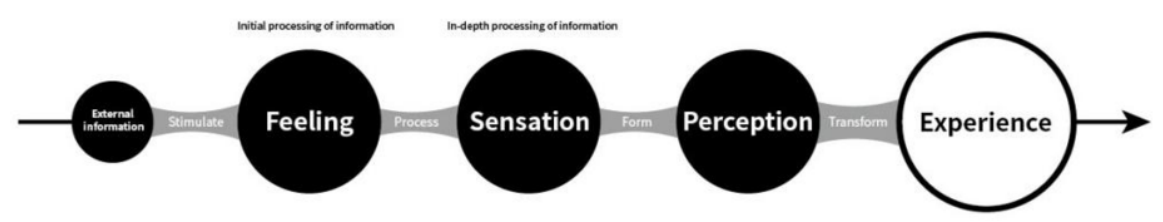

Figure 1. The formation process of perceptual experience.

\section{Method}

\subsection{Experimental Subject}

In order to create the contrast between material perceptual experience and its physical property, we select wood, with fixed label of hardness and heaviness in general perception, as the target material. Through changing two main perceptual elements of 
visual and tactile perception, the author hope to construct a softening perceptual experience. Among the wood materials, the beech wood with the advantages of light and soft appearance, low cost, moderate hardness and low cracking rate is selected as the specific research target after comparing the grain, cost, cracking rate and softness degree.

\subsection{Experiment Preparation}

In order to determine the key elements of visual and tactile perception of beech wood, 110 users are invited before the experience, including 49 males and 61 females, whom are 18-45 years old, with normal or corrected vision, without color blindness or color weakness, and without physical hand defects. Through questionnaire, we collect their main concern of the visual and tactile perceptual elements and rank the results. Four key elements of visual perception are color, texture and grain, roughness and shape, and four key elements of tactile perception are weight, roughness degree, surface softness degree and deformation degree. The result as follow:
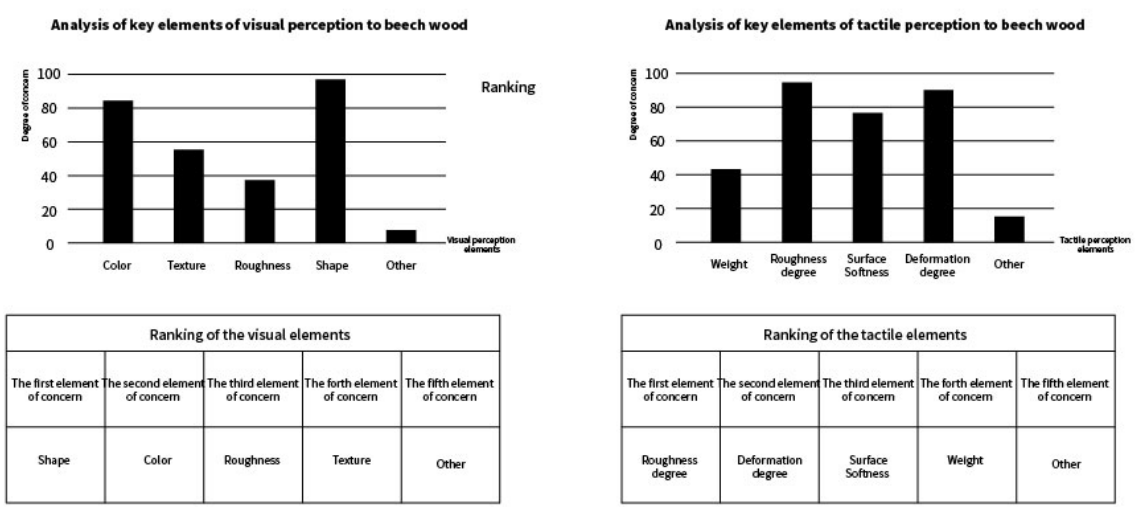

Figure 2. Results of key elements of beech wood visual and tactile perception

According to the survey, among the visual perception elements of beech wood, the users concerned most is shape, followed by color, texture and roughness. In the ranking of the elements, shape is the first, followed by color, roughness and texture. Among the tactile perception elements of beech wood, the users concerned most is roughness degree, deformation degree, surface softness degree, weight. In the ranking of the elements, roughness degree is the first, followed by deformation degree, surface softness degree, weight. Thus, shape and color, the key visual perceptual elements, deformation degree and roughness degree, the key tactile perceptual elements, will be variables for following experience, and we will research their effects to softening perceptual experience of beech wood.

\subsection{Experiment Process}

Shape, color, deformation degree and surface roughness degree of beech wood will be a single variable separately in the experience. We will explore whether they can achieve softening perceptual experience in contrast to its physical property.

- Shape as a single variable: combining the existing common processing methods of wood, the beech wood will be processed into four major types, wood-wool, stick, slice and block, among which the stick wood will be processed into 
straight stick and curved stick; the slice wood will be processed into round, square, triangular, hexagonal and wavy slice; and the block wood will be processed into sphere, cube, trigonous, hexagonal and wavy block. A total of 13 groups in different shapes will be coded.

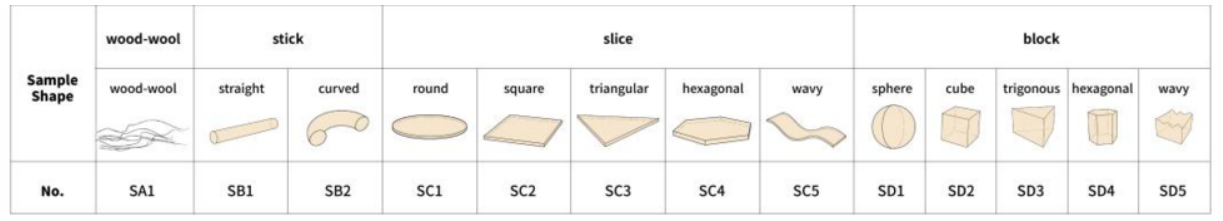

Figure 3. Codes of different shapes

- Color as a single variable: according to 12 color circle, we select primary colors of red, yellow and blue, and other color of orange, purple and green, as the experimental colors. Since white and black are common color in products but not in the circle, so we also added them in. As a result, a total of 8 colors are confirmed as the experimental colors. These color pastes will be added to the wood water-based lacquer, dipped by the sponge and rubbed onto eight $5 * 5 * 0.5 \mathrm{~cm}$ thick square beech wood slices and coded.

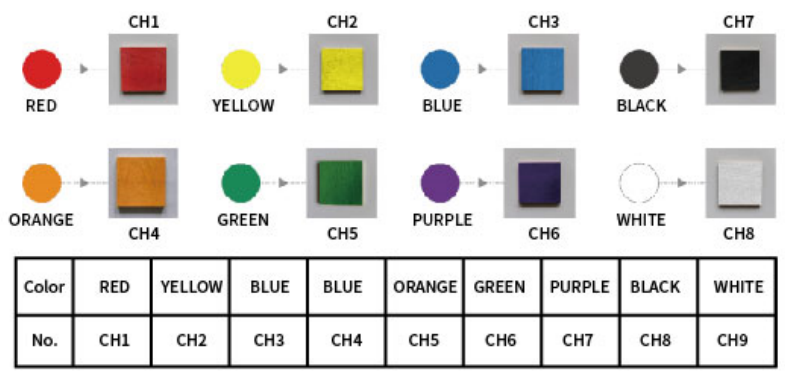

Figure 4. Codes of different colors

- Roughness degree as a single variable: on the base of $5 * 5 * 0.5 \mathrm{~cm}$ square raw wood-colored beech wood slice as the sample, roughness degree will be as a single variable. Through sanding 6 pieces of square beech wood with 60,100 , $180,280,400,800$ and $1500 \mathrm{cw}$ by woodworking water-grit sandpaper for 20 minutes, experimental samples with different surface roughness degree are made and coded.

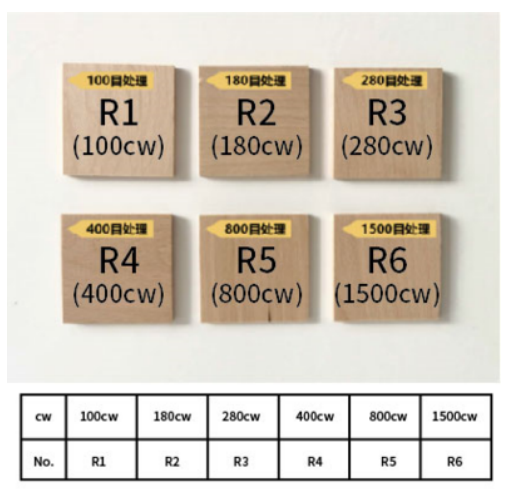

Figure 5. Codes of different roughness 
- Deformation degree as a single variable: on the base of $5 * 5 * 2 \mathrm{~cm}$ square raw wood-colored beech wood slice as the sample, deformation degree will be as a single variable. Those slices will be processed into different thicknesses $(1,2$, $3,4,5 \mathrm{~mm}$ ) for deformation prediction test, and it's found that the deformation variables of thicknesses above $4 \mathrm{~mm}$ are very thin, resulting in insufficient experimental samples. In order to enlarge the deformation variables to obtain sufficient gradient samples, we select $2 \mathrm{~mm}$ as the base thickness and processed the beech wood slice into grille with different density by laser cutting to obtain 6 kinds of samples with different deformation degree, and code for them.

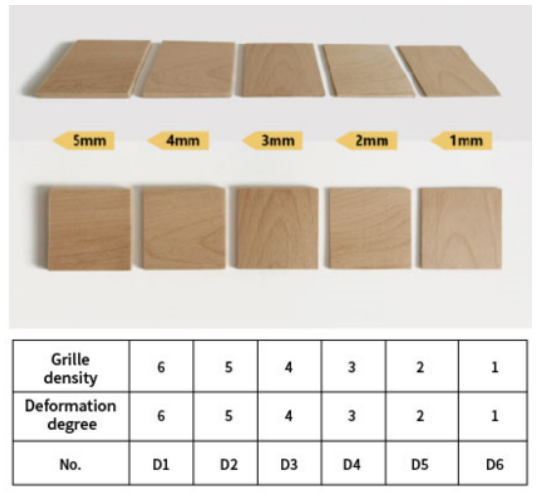

Figure 6. Codes of different deformation degree

After confirming the contents of each perceptual element variable, total of 30 testers are selected randomly to evaluate the softening perceptual experience degree. 7-point Likert scale, with scores ranging from 1(not soft at all) to 7(very soft), is adapted for the evaluation. After the evaluation, the results will be imported into SPSS software for descriptive statistics and analysis of variance (ANOVA). For further investigation of the differences in each group on softening perceptual experience degree, post hoc test analysis of the experimental data is conducted through the LDS method. And in order to measure the evaluation consistency of the association within the group, the Kendall coordination coefficient test is also conducted separately to the tester (evaluator) and contents(evaluation subjects).

\section{Results}

\subsection{Results of shape as a single variable}

According to the results, different groups of samples showed the significance $(p<0.05)$ for all of the data, implying that different shapes of beech wood samples produced significant differences in the softening perceptual experience degree. the average value and median scores of A1 (wood-wool), B2 (curved stick), C5 (wavy slice) and D5 (wavy block) are relatively high, indicating that these shapes cause a certain visual softening perceptual experience. 
Table 1. Data of descriptive statistics and analysis of variance (Shape as a single variable).

\begin{tabular}{|c|c|c|c|}
\hline No. & Average value & Standard deviation & Median \\
\hline SA1 & 4.633 & 0.999 & 5 \\
\hline SB1 & 1.133 & 0.346 & 1 \\
\hline SB2 & 3.333 & 0.711 & 3 \\
\hline SC1 & 1.8 & 0.484 & 2 \\
\hline SC2 & 1.267 & 0.583 & 1 \\
\hline $\mathrm{SC} 3$ & 1.3 & 0.535 & 1 \\
\hline SC4 & 1.2 & 0.484 & 1 \\
\hline SC5 & 4.5 & 0.9 & 5 \\
\hline SD1 & 1.2 & 0.407 & 1 \\
\hline SD2 & 1.167 & 0.379 & 1 \\
\hline SD3 & 1.233 & 0.568 & 1 \\
\hline SD4 & 1.3 & 0.596 & 1 \\
\hline SD5 & 4.567 & 0.898 & 5 \\
\hline \multicolumn{4}{|c|}{ ANOVA } \\
\hline & & \multicolumn{2}{|l|}{158.06} \\
\hline & & \multicolumn{2}{|l|}{$0.000 * *$} \\
\hline
\end{tabular}

$* \mathrm{p}<0.05 * * \mathrm{p}<0.01$

For further investigation of the differences between different shapes on softening perceptual experience degree, post hoc test analysis of the experimental data is conducted through the LDS method. Here is the result:

Table 2. Post hoc test analysis data (Shape as a single variable).

\begin{tabular}{|c|c|c|c|c|c|}
\hline (I)No. & (J)No. & (I)Average value & (J)Average value & (I-J)Difference & $\mathbf{p}$ \\
\hline SA1 & SB1 & 4.633 & 1.133 & 3.5 & $0.000 * *$ \\
\hline SA1 & SB2 & 4.633 & 3.333 & 1.3 & $0.000 * *$ \\
\hline SA1 & SC1 & 4.633 & 1.8 & 2.833 & $0.000 * *$ \\
\hline SC5 & SD1 & 4.5 & 1.2 & 3.3 & $0.000 * *$ \\
\hline SC5 & SD2 & 4.5 & 1.167 & 3.333 & $0.000 * *$ \\
\hline SC5 & SD3 & 4.5 & 1.233 & 3.267 & $0.000 * *$ \\
\hline SC5 & SD4 & 4.5 & 1.3 & 3.2 & $0.000 * *$ \\
\hline SC5 & SD5 & 4.5 & 4.567 & -0.067 & 0.687 \\
\hline SD1 & SD2 & 1.2 & 1.167 & 0.033 & 0.84 \\
\hline SD1 & SD3 & 1.2 & 1.233 & -0.033 & 0.84 \\
\hline SD1 & SD4 & 1.2 & 1.3 & -0.1 & 0.545 \\
\hline SD1 & SD5 & 1.2 & 4.567 & -3.367 & $0.000 * *$ \\
\hline SD2 & SD3 & 1.167 & 1.233 & -0.067 & 0.687 \\
\hline SD2 & SD4 & 1.167 & 1.3 & -0.133 & 0.42 \\
\hline $\mathrm{SD} 2$ & SD5 & 1.167 & 4.567 & -3.4 & $0.000 * *$ \\
\hline SD3 & SD4 & 1.233 & 1.3 & -0.067 & 0.687 \\
\hline SD3 & SD5 & 1.233 & 4.567 & -3.333 & $0.000 * *$ \\
\hline SD4 & SD5 & 1.3 & 4.567 & -3.267 & $0.000 * *$ \\
\hline
\end{tabular}

According to the results, different groups of samples all showed significance $(p<0.05)$, implying that different groups of samples have differences to the data, 
which further proves that different shapes of beech wood samples produce significantly different ratings of the degree of softening perceptual experience of the user's visual perception.

Table 3. Kendall Coordination coefficient test data (Shape as a single variable).

\begin{tabular}{ccccc}
\hline Tester(user) & Object(processed sample) & Kendall coordination coefficient & Statistic $x^{2}$ & p \\
\hline 30 & 13 & 0.787 & 283.294 & $0.000^{* *}$ \\
\hline$* \mathrm{p}<0.05 * * \mathrm{p}<0.01$ & & & &
\end{tabular}

To further measure the consistency of the evaluation within the group, the Kendall coordination coefficient test is conducted among the tester(user) and the object(processed sample). The Kendall coordination coefficient test shows significance $(\mathrm{p}=0.000<0.05)$, indicating that 30 evaluation is consistent. And Kendall coordination coefficient is 0.787 , which is between $0.6 \sim 0.8$, indicating a high degree of the evaluation consistency.

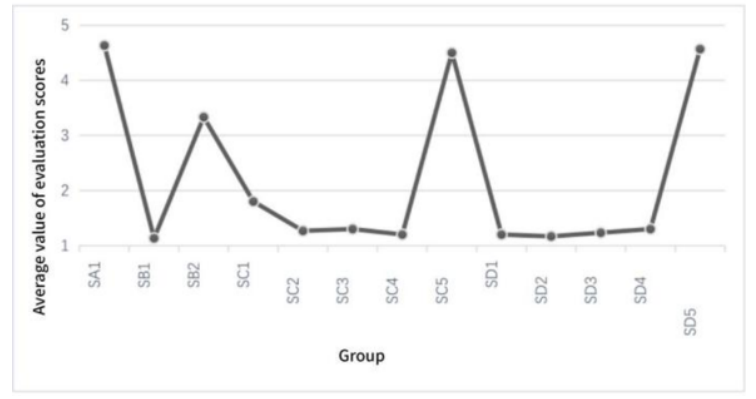

Figure 7. Average value of evaluation scores of different shape groups.

Combined with the experimental data analysis and average value of evaluation score, different shapes of beech samples have a significant effect on the degree of softening perceptual experience produced by the user's visual perception, among which the influence of wood-wool, curved stick, wavy slice and wavy block is more obvious.

\subsection{Results of color as a single variable}

Through changing the color of beech wood(a single variable), we hope to research the effect of different colors to the softening perceptual experience on the user's visual perception.

Table 4. Data of descriptive statistics and analysis of variance (Color as a single variable)

\begin{tabular}{lccc}
\hline No. & Average value & Standard deviation & Median \\
\hline CH1 & 1.3 & 0.535 & 1 \\
CH2 & 3.467 & 0.73 & 3 \\
CH3 & 1.133 & 0.346 & 1 \\
CH4 & 4.5 & 0.9 & 5 \\
CH5 & 1.267 & 0.521 & 1 \\
CH6 & 1.3 & 0.596 & 1 \\
CH7 & 1.2 & 0.407 & 1 \\
CH8 & 4.8 & 0.961 & 5 \\
\hline
\end{tabular}




\begin{tabular}{rll}
\hline & ANOVA \\
\hline & $\mathrm{F}$ & 178.574 \\
& $\mathrm{p}$ & $0.000 * *$ \\
\hline
\end{tabular}

$* \mathrm{p}<0.05 * * \mathrm{p}<0.01$

According to the results, different groups of samples all shows their significance $(p<0.05)$, implying that different color of beech samples produce significant differences in the degree of softening perceptual experience scores on the users' visual perception. Based on the average value and median of the scores, it can be seen that the most significant effect is white, followed by orange and yellow.

For further investigation of the differences between different colors on softening perceptual experience degree, post hoc test analysis of the experimental data is conducted through the LDS method. Here is the result:

Table 5. Post hoc test analysis data (Color as a single variable).

\begin{tabular}{|c|c|c|c|c|c|}
\hline (I)No. & (J)No. & $\begin{array}{c}\text { (I)Average } \\
\text { value }\end{array}$ & $\begin{array}{c}\text { (J)Average } \\
\text { value }\end{array}$ & $\begin{array}{c}(\mathrm{I}- \\
\text { J)Difference }\end{array}$ & $\mathbf{p}$ \\
\hline $\mathrm{CH} 1$ & CH 2 & 1.3 & 3.467 & -2.167 & $0.000 * *$ \\
\hline $\mathrm{CH} 1$ & CH 3 & 1.3 & 1.133 & 0.167 & 0.328 \\
\hline $\mathrm{CH} 1$ & $\mathrm{CH} 4$ & 1.3 & 4.5 & -3.2 & $0.000 * *$ \\
\hline $\mathrm{CH} 1$ & CH 5 & 1.3 & 1.267 & 0.033 & 0.845 \\
\hline $\mathrm{CH} 1$ & CH 6 & 1.3 & 1.3 & 0 & 1 \\
\hline $\mathrm{CH} 1$ & $\mathrm{CH} 7$ & 1.3 & 1.2 & 0.1 & 0.557 \\
\hline $\mathrm{CH} 1$ & $\mathrm{CH} 8$ & 1.3 & 4.8 & -3.5 & $0.000 * *$ \\
\hline $\mathrm{CH} 2$ & $\mathrm{CH} 3$ & 3.467 & 1.133 & 2.333 & $0.000 * *$ \\
\hline $\mathrm{CH} 2$ & $\mathrm{CH} 4$ & 3.467 & 4.5 & -1.033 & $0.000 * *$ \\
\hline $\mathrm{CH} 2$ & CH 5 & 3.467 & 1.267 & 2.2 & $0.000 * *$ \\
\hline $\mathrm{CH} 2$ & CH 6 & 3.467 & 1.3 & 2.167 & $0.000 * *$ \\
\hline $\mathrm{CH} 2$ & CH 7 & 3.467 & 1.2 & 2.267 & $0.000 * *$ \\
\hline $\mathrm{CH} 2$ & $\mathrm{CH} 8$ & 3.467 & 4.8 & -1.333 & $0.000 * *$ \\
\hline $\mathrm{CH} 3$ & $\mathrm{CH} 4$ & 1.133 & 4.5 & -3.367 & $0.000^{* *}$ \\
\hline $\mathrm{CH} 3$ & $\mathrm{CH} 5$ & 1.133 & 1.267 & -0.133 & 0.433 \\
\hline $\mathrm{CH} 3$ & $\mathrm{CH} 6$ & 1.133 & 1.3 & -0.167 & 0.328 \\
\hline $\mathrm{CH} 3$ & $\mathrm{CH} 7$ & 1.133 & 1.2 & -0.067 & 0.695 \\
\hline $\mathrm{CH} 3$ & $\mathrm{CH} 8$ & 1.133 & 4.8 & -3.667 & $0.000 * *$ \\
\hline $\mathrm{CH} 4$ & $\mathrm{CH} 5$ & 4.5 & 1.267 & 3.233 & $0.000 * *$ \\
\hline $\mathrm{CH} 4$ & CH 6 & 4.5 & 1.3 & 3.2 & $0.000 * *$ \\
\hline $\mathrm{CH} 4$ & $\mathrm{CH} 7$ & 4.5 & 1.2 & 3.3 & $0.000 * *$ \\
\hline $\mathrm{CH} 4$ & $\mathrm{CH} 8$ & 4.5 & 4.8 & -0.3 & 0.079 \\
\hline $\mathrm{CH} 5$ & $\mathrm{CH} 6$ & 1.267 & 1.3 & -0.033 & 0.845 \\
\hline $\mathrm{CH} 5$ & $\mathrm{CH} 7$ & 1.267 & 1.2 & 0.067 & 0.695 \\
\hline $\mathrm{CH} 5$ & $\mathrm{CH} 8$ & 1.267 & 4.8 & -3.533 & $0.000 * *$ \\
\hline CH6 & $\mathrm{CH} 7$ & 1.3 & 1.2 & 0.1 & 0.557 \\
\hline CH6 & $\mathrm{CH} 8$ & 1.3 & 4.8 & -3.5 & $0.000 * *$ \\
\hline $\mathrm{CH} 7$ & $\mathrm{CH} 8$ & 1.2 & 4.8 & -3.6 & $0.000 * *$ \\
\hline
\end{tabular}

According to the results, there are no significant differences between $\mathrm{CH} 1$ (red), $\mathrm{CH} 3$ (blue), $\mathrm{CH} 5$ (green), $\mathrm{CH} 6$ (purple), and CH7 (black), and the other different colors are significantly different from each other. It is further determined that the same color 
beech wood samples produced significant differences in the degree of softening perceptual experience scores on visual perception by users.

Table 6. Kendall Coordination coefficient test data (Color as a single variable).

\begin{tabular}{|c|c|c|c|c|}
\hline Tester(user) & $\begin{array}{c}\text { Object(processed } \\
\text { sample) }\end{array}$ & $\begin{array}{c}\text { Kendall coordination } \\
\text { coefficient }\end{array}$ & Statistics $x^{2}$ & $\mathbf{p}$ \\
\hline 30 & 8 & 0.836 & 175.511 & $0.000 * *$ \\
\hline
\end{tabular}

After verifying the evaluation consistency through the Kendall coordination coefficient test, it showed the significance $(p=0.000<0.05)$, implying that the evaluations of the 30 evaluators are correlated, which indicating that the evaluations are consistent. And the Kendall coordination coefficient was 0.836 , which is over 0.8 , indicating a strong degree of evaluation consistency.

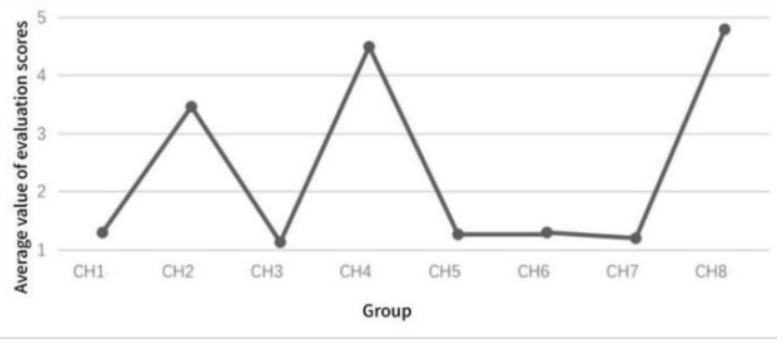

Figure 8. Average value of evaluation scores of different color groups.

Combined with the experimental data analysis and the average value of evaluation scores, different colors of beech wood samples have a significant impact on the degree of softening perceptual experience to the user's visual perception. White, orange and yellow have a stronger effect, among which the effect of white and orange is similar. While red, blue, green, purple and black have weaker effect to softening perceptual experience.

\subsection{Results of roughness as a single variable}

Through changing the roughness of beech wood(a single variable), we hope to research the effect of different roughness to the softening perceptual experience on the user's visual perception.

Table 7. Data of descriptive statistics and analysis of variance (Roughness as a single variable).

\begin{tabular}{|c|c|c|c|}
\hline No. & Average value & Standard deviation & Median \\
\hline $\mathrm{R} 1$ & 1.233 & 0.43 & 1 \\
\hline $\mathrm{R} 2$ & 1.133 & 0.346 & 1 \\
\hline $\mathrm{R} 3$ & 1.167 & 0.379 & 1 \\
\hline $\mathrm{R} 4$ & 1.267 & 0.521 & 1 \\
\hline R5 & 1.467 & 0.571 & 1 \\
\hline R6 & 1.767 & 0.728 & 2 \\
\hline \multicolumn{4}{|c|}{ ANOVA } \\
\hline & & \multicolumn{2}{|c|}{6.57} \\
\hline & & \multicolumn{2}{|c|}{$0.000 * *$} \\
\hline
\end{tabular}

$* \mathrm{p}<0.05 * * \mathrm{p}<0.01$ 
The mean and median of the evaluation scores show that the beech wood samples with different roughness have lower scores on the degree of softening perceptual experience on the users' tactile perception, which shows a weak influence. From the ANOVA results, it can be seen that the different roughness samples show the significance $(p<0.05)$ for ranking the degree of softening perceptual experience on tactile perception by users, implying the differences for the evaluation scores in different groups.

For further investigation of the differences among samples, post hoc test analysis of the experimental data is conducted through the LDS method. Here is the result:

Table 8. Post hoc test analysis data (Roughness as a single variable).

\begin{tabular}{cccccc}
\hline (I)No. & (J)No. & $\begin{array}{c}\text { (I)Average } \\
\text { value }\end{array}$ & $\begin{array}{c}\text { (J)Average } \\
\text { value }\end{array}$ & $\begin{array}{c}\text { (I- } \\
\text { J)Difference }\end{array}$ & p \\
\hline R1 & R2 & 1.233 & 1.133 & 0.1 & 0.451 \\
R1 & R3 & 1.233 & 1.167 & 0.067 & 0.615 \\
R1 & R4 & 1.233 & 1.267 & -0.033 & 0.801 \\
R1 & R5 & 1.233 & 1.467 & -0.233 & 0.08 \\
R1 & R6 & 1.233 & 1.767 & -0.533 & $0.000^{* *}$ \\
\hline R2 & R3 & 1.133 & 1.167 & -0.033 & 0.801 \\
R2 & R4 & 1.133 & 1.267 & -0.133 & 0.315 \\
R2 & R5 & 1.133 & 1.467 & -0.333 & $0.013 *$ \\
R2 & R6 & 1.133 & 1.767 & -0.633 & $0.000^{* *}$ \\
\hline R3 & R4 & 1.167 & 1.267 & -0.1 & 0.451 \\
R3 & R5 & 1.167 & 1.467 & -0.3 & $0.025^{*}$ \\
R3 & R6 & 1.167 & 1.767 & -0.6 & $0.000^{* *}$ \\
\hline R4 & R5 & 1.267 & 1.467 & -0.2 & 0.132 \\
R4 & R6 & 1.267 & 1.767 & -0.5 & $0.000^{* *}$ \\
\hline R5 & R6 & 1.467 & 1.767 & -0.3 & $0.025^{*}$ \\
\hline
\end{tabular}

$* \mathrm{p}<0.05 * * \mathrm{p}<0.01$

The post hoc data analysis shows that small difference between adjacent groups(except for R5 and R6), indicating low differences between changes in roughness on visual perception producing softening perceptual experience by users, and implying that the effect of changes in different roughness is weak.

Table 9. Kendall Coordination coefficient test data (Roughness as a single variable).

\begin{tabular}{ccccc}
\hline Tester(user) & $\begin{array}{c}\text { Object(processed } \\
\text { sample) }\end{array}$ & $\begin{array}{c}\text { Kendall coordination } \\
\text { coefficient }\end{array}$ & Statistics $\chi^{2}$ & $\mathbf{p}$ \\
\hline 30 & 6 & 0.261 & 39.109 & $0.000^{* *}$ \\
\hline$* \mathrm{p}<0.05 * * \mathrm{p}<0.01$ & & & &
\end{tabular}

The Kendall coordination coefficient test is used to study the evaluation consistency. From the above table, it can be seen that the Kendall coordination coefficient test showed significance $(\mathrm{p}=0.000<0.05)$, which means that the evaluations of 30 evaluators are correlated, i.e., it indicates that the evaluations are consistent. And the Kendall coordination coefficient is 0.261 , which is between $0.2 \sim 0.4$, indicating an average degree of evaluation consistency. 


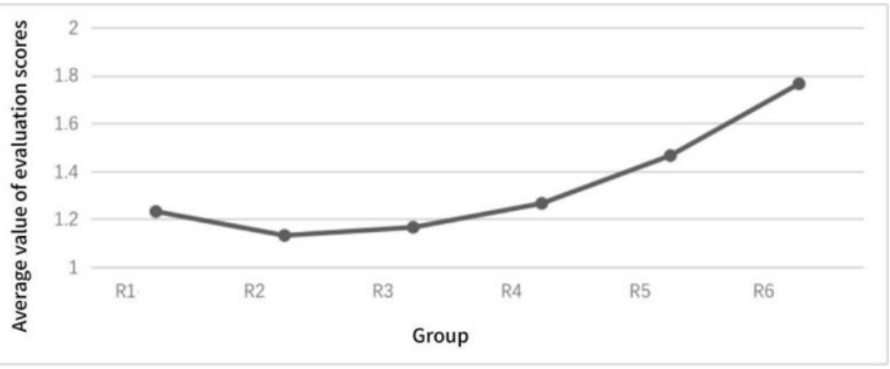

Figure 9. Average value of evaluation scores of different roughness groups.

Combined with the average value, the beech samples with different roughness have a weak effect on the degree of softening perceptual experience on tactile perception, and the variability between beech samples with different roughness is relatively small, implying that although the user pays more attention to the roughness, it plays little effect on the degree of softening perceptual experience and is difficult to be used as a key element in regulating material perception.

\subsection{Results of deformation degree as a single variable}

Through changing the deformation degree of beech wood(a single variable), we hope to research the effect of different deformation degree to the softening perceptual experience on the user's visual perception.

Table 10. Data of descriptive statistics and analysis of variance (Deformation degree as a single variable).

\begin{tabular}{cccc}
\hline No. & Average value & Standard deviation & Median \\
\hline D1 & 5.6 & 0.675 & 5.5 \\
D2 & 5.233 & 0.504 & 5 \\
D3 & 4.233 & 0.43 & 4 \\
D4 & 3.833 & 0.379 & 4 \\
D5 & 2.333 & 0.711 & 2 \\
D6 & 2.067 & 0.944 & 2 \\
\hline & ANOVA & & 212.418 \\
\hline
\end{tabular}

${ }^{*} \mathrm{p}<0.05 * * \mathrm{p}<0.01$

According to the average value and median, it can be seen that, the larger the deformation is, the stronger influence on the degree of softening perceptual experience from the user's tactile perception is, and conversely the smaller the deformation is, the weaker influence is, which imply that the larger the deformation degree is, the easier to feel soft, and the smaller the deformation degree is, the harder to feel soft. According to the results of ANOVA, different groups of samples showed significance $(p<0.05)$ for the evaluation scores, implying that different shape variables of beech wood samples on the user's tactile perception produced significant differences in the degree of softening perceptual experience scores.

For further investigation of the differences among samples, post hoc test analysis of the experimental data is conducted through the LDS method. Here is the result: 
Table 11. Post hoc test analysis data (Deformation degree as a single variable).

\begin{tabular}{cccccc}
\hline (I)No. & (J)No. & $\begin{array}{c}\text { (I)Average } \\
\text { value }\end{array}$ & $\begin{array}{c}\text { (J)Average } \\
\text { value }\end{array}$ & $\begin{array}{c}(\text { I- } \\
\text { J)Difference }\end{array}$ & p \\
\hline D1 & D2 & 5.6 & 5.233 & 0.367 & $0.012^{*}$ \\
D1 & D3 & 5.6 & 4.233 & 1.367 & $0.000^{* *}$ \\
D1 & D4 & 5.6 & 3.833 & 1.767 & $0.000^{* *}$ \\
D1 & D5 & 5.6 & 2.267 & 3.333 & $0.000^{* *}$ \\
D1 & D6 & 5.6 & 1.967 & 3.633 & $0.000^{* *}$ \\
\hline D2 & D3 & 5.233 & 4.233 & 1 & $0.000^{* *}$ \\
D2 & D4 & 5.233 & 3.833 & 1.4 & $0.000^{* *}$ \\
D2 & D5 & 5.233 & 2.267 & 2.967 & $0.000^{* *}$ \\
D2 & D6 & 5.233 & 1.967 & 3.267 & $0.000^{* *}$ \\
\hline D3 & D4 & 4.233 & 3.833 & 0.4 & $0.006 * *$ \\
D3 & D5 & 4.233 & 2.267 & 1.967 & $0.000^{* *}$ \\
D3 & D6 & 4.233 & 1.967 & 2.267 & $0.000^{* *}$ \\
\hline D4 & D5 & 3.833 & 2.267 & 1.567 & $0.000^{* *}$ \\
D4 & D6 & 3.833 & 1.967 & 1.867 & $0.000^{* *}$ \\
\hline D5 & D6 & 2.267 & 1.967 & 0.3 & $0.040 *$ \\
\hline p $<0.05 * * \mathrm{p}<0.01$ & & & & \\
\hline
\end{tabular}

According to the post hoc test analysis data, samples with different deformation degree show significance $(\mathrm{p}<0.05)$, which means that the degree of difference between different samples is relatively large, further indicating that the element of deformation degree has a very significant impact on the degree of softening perceptual experience to the user's tactile perception.

Table 12. Kendall Coordination coefficient test data (Deformation degree as a single variable).

\begin{tabular}{ccccc}
\hline Tester(user) & $\begin{array}{c}\text { Object(processed } \\
\text { sample) }\end{array}$ & $\begin{array}{c}\text { Kendall coordination } \\
\text { coefficient }\end{array}$ & Statistics $\chi^{2}$ & p \\
\hline 30 & 6 & 0.901 & 135.189 & $0.000^{* *}$ \\
\hline$* \mathrm{p}<0.05 * * \mathrm{p}<0.01$ & & & &
\end{tabular}

The results are examined through using the Kendall coordination coefficient test to study the evaluation consistency shows that the Kendall coordination coefficient test showed significance $(p=0.000<0.05)$, which means that the evaluations of the 30 evaluators are correlated, it indicates that the evaluations are consistent. And the Kendall coordination coefficient was 0.901 , which is greater than 0.8 , indicating a strong degree of evaluation consistency.

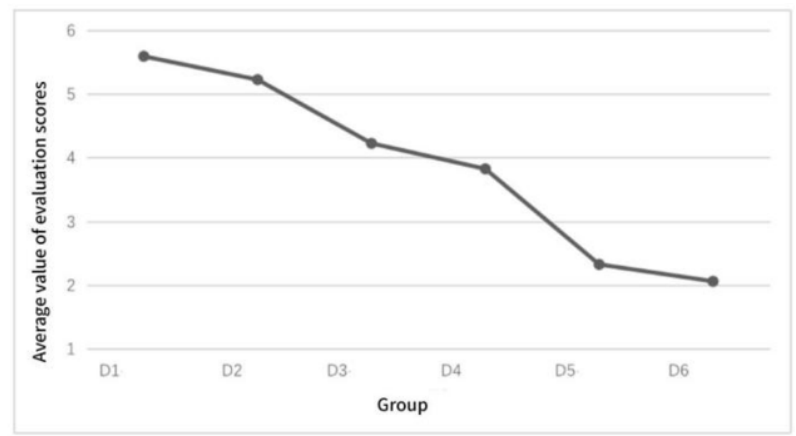

Figure 10. Average value of evaluation scores of different deformation degree groups. 
Combined with the average value of evaluation scores, beech wood samples with different deformation degree have a significant impact on the user's tactile perception of softening perceptual experience, the greater deformation degree is, the higher the degree of softening perceptual experience is, and vice versa, the smaller deformation degree is, the lower the degree of softening perceptual experience is. The effect of the tactile perception element of deformation degree is obvious and can be used as a key direction to change the innovation of beech wood perception experience.

\section{Conclusion}

This paper demonstrates the effect of different variations of shape, color, roughness and deformation degree on shaping the softening perceptual experience of beech wood materials through the change of visual and tactile perceptual elements. Among the shape variations of visual perceptual elements, wood-wool has the strongest effect on the softening perceptual experience, followed by wavy block, wavy slice and curved stick. Among the color variations of visual perceptual elements, white has the strongest effect on the softening perceptual experience, followed by orange and yellow. Among the tactile perceptual focus elements (roughness and deformation degree), roughness has a very weak effect on the softening perceptual experience, while deformation degree has a very strong effect on it; the greater the deformation degree is, the greater the effect on the softening perceptual experience is, and conversely the smaller the deformation degree is, the weaker the effect on the softening perceptual experience is.

Combined with the above experimental results, it proves that by changing the physical properties of beech wood, it is possible to create a softening perceptual experience. This provides an example for material perceptual experience innovation, which enables designers to apply materials more flexibly in product design to create a perceptual experience that is different from the physical properties of the material and gives new perceptual characteristics to the material, while conforming to the function and manner of the product, and greatly broadens the boundaries of material innovation and brings new directions to it.

\section{References}

[1] Xu Demin, Liu Yan. Exploring the Application of Design Materials based on Application Function and Sensory Experience[J]. Beauty and Times(1), 2017, 712(08):27-29.

[2] Lang Lijuan, Jiang Wen. Innovative Design of Products Based on Material Properties[J]. Journal of Guangdong University of Technology (Social Science Edition), 2012,12(1):77-80.

[3] Li Bin. Material Aesthetics in Art Design[J]. Literature and Art Review, 2010(5X): 135-138.

[4] ETER F. Designing the 21st Century [M]. Germany: GmbH. 2001.

[5] Zheng Ziyun. Research on Product Design Innovation Method Based on Material Perception Experience[J]. Packaging Engineering, 2017, 38(2): 197-200.

[6] Daniel Schacter, Daniel Gilbert, Daniel Wegner. Psychology[M]. New York, NY : Worth Publishers, 2011.

[7] Peng Ziling. General Psychology [M]. Beijing Normal University Press. 2004: 78.

[8] Huang Xiting, Zheng Yong. Introduction to Psychology [M]. People's Education Press. 2015: 263. 